\title{
Mannan-Binding Lectin in Cardiovascular Disease
}

\author{
Izabela Pągowska-Klimek $^{1}$ and Maciej Cedzyński ${ }^{2}$ \\ ${ }^{1}$ Department of Anesthesiology and Intensive Care, Polish Mother's Memorial Hospital Institute, \\ Rzgowska 281/289, 93-338 Łódź, Poland \\ ${ }^{2}$ Laboratory of Immunobiology of Infections, Institute of Medical Biology, Polish Academy of Sciences, \\ Lodowa 106, 93-232 Łódź, Poland
}

Correspondence should be addressed to Izabela Pągowska-Klimek; izabelapag@gmail.com

Received 27 January 2014; Accepted 10 April 2014; Published 30 April 2014

Academic Editor: Robert M. Starke

Copyright (C) 2014 I. Pągowska-Klimek and M. Cedzyński. This is an open access article distributed under the Creative Commons Attribution License, which permits unrestricted use, distribution, and reproduction in any medium, provided the original work is properly cited.

\begin{abstract}
Cardiovascular disease remains the leading cause of mortality and morbidity worldwide so research continues into underlying mechanisms. Since innate immunity and its potent component mannan-binding lectin have been proven to play an important role in the inflammatory response during infection and ischaemia-reperfusion injury, attention has been paid to its role in the development of cardiovascular complications as well. This review provides a general outline of the structure and genetic polymorphism of MBL and its role in inflammation/tissue injury with emphasis on associations with cardiovascular disease. MBL appears to be involved in the pathogenesis of atherosclerosis and, in consequence, coronary artery disease and also inflammation and tissue injury after myocardial infarction and heart transplantation. The relationship between MBL and disease is rather complex and depends on different genetic and environmental factors. That could be why the data obtained from animal and clinical studies are sometimes contradictory proving not for the first time that innate immunity is a "double-edge sword," sometimes beneficial and, at other times disastrous for the host.
\end{abstract}

\section{Mannan-Binding Lectin: An Overview of Structure and Synthesis}

Historically, innate immunity was identified as the firstline defense system, protecting an organism from invading pathogens and abnormal self-derived components. Its immediate response prevents the spreading of progressive systemic infection after contact with pathogens. Furthermore, it takes part in the clearance of damaged cells and tissues, preventing the development of chronic inflammation, cancer, or uncontrolled autoimmune responses. There are two phases of the innate immune response: recognition and elimination of targets. The innate immunity system functions via a network of cellular and humoral factors. Mannanbinding lectin (MBL), also known as mannose-binding lectin or mannan- (mannose-) binding protein (MBP), is a soluble (humoral) pattern-recognition molecule thought to be an important component of the innate immune system. MBL has opsonic activity and, in cooperation with MBL-associated serine proteases (MASPs), the ability to activate complement via the lectin pathway.

Mannan-binding lectin belongs to the collectin family, a group of C-type lectins also possessing a collagen-like helical domain. Human MBL exists as a series of oligomers of $2-$ 6 subunits, built up from three identical polypeptide chains (24 kDa, 228 amino acids each). The apparent molecular weights of these oligomers range from approx. 150,000 to approx. 450,000, taking into account glycosylation. It forms a "bouquet-like" structure. MBL, like other collectins, is characterized by the presence of four regions. (1) The short Nterminal cysteine-rich domain is responsible for the arrangement of subunits in the oligomer, dependent on disulphide bonds; this region consists of 21 amino acids, including three Cys residues. (2) The collagen-like region interacts with MASPs; it consists of 59 amino acids (among them 19 Gly$\mathrm{X}-\mathrm{Y}$ triplets); this domain is glycosylated. (3) Next, an $\alpha$ helical "neck" region (30 amino acids) stabilizes polypeptide chains within a structural subunit. (4) The C-terminal 
carbohydrate-recognition domain (CRD) is responsible for pattern recognition and consists of 118 amino acids [1-6]. MBL binds with the highest affinity to D-mannose, $\mathrm{N}$-acetylD-glucosamine, and L-fucose which allows the specific recognition of numerous polysaccharides and glycoconjugates like bacterial lipopolysaccharides, capsular polysaccharides, fungal mannans, and so forth. It moreover recognizes some phospholipids, Neisseria outer membrane proteins, and DNA of apoptotic cells [7-9]. Mannan-binding lectin is synthesized by hepatocytes and secreted into the blood in an oligomeric form. Moreover, specific mRNA has been found in bone marrow, fetal lung, small intestine, and testis [10]. Its synthesis is controlled by the $M B L 2$ gene, located on chromosome 10 (10q11.2) and regulated in a similar manner to acute phase proteins. The plasma concentration of MBL can increase up to 3 -fold in response to infection. In healthy individuals, an average plasma (serum) level is approx. $1 \mu \mathrm{g} / \mathrm{mL}$; however it ranges from $<0.1 \mu \mathrm{g} / \mathrm{mL}$ up to $>5 \mu \mathrm{g} / \mathrm{mL}$. The $M B L 2$ gene contains 4 exons and 3 introns. Most mammals (but not humans or chimpanzees) synthesize two MBL forms: A and C. Human MBL resembles the $\mathrm{C}$ form. The $M B L 1$ pseudogene (not expressed), corresponding to the A form, has been found in the human genome. Exon 1 of the MBL2 gene encodes the signal peptide, the cysteine-rich domain, and part of the collagen-like region. Exon 2 encodes the remaining part of the latter. Exon 3 encodes the neck region while exon 4 encodes the CRD $[3-6,11,12]$.

MBL deficiency, believed to be the most common human immunodeficiency, markedly depends on MBL2 gene point mutations in codons 52,54, and 57 of exon 1 . These variants, giving dominant alleles $\mathrm{D}, \mathrm{B}$, and $\mathrm{C}$, respectively (commonly designated collectively as $\mathrm{O}$; the wild-type is designated as A), lead to disruption of the collagen domain structure. This, in consequence, prevents oligomerization of the basic triplet polypeptide subunit (and therefore normal interaction with MASPs) resulting in diminished complement activation and opsonic activity [6, 13-15].

A shortened biological half-life of the protein is a reflection of increased sensitivity to serum metalloproteases [16]. As well as the aforementioned mutations, polymorphisms in the promoter region (at positions -550 and -221 ; variants $\mathrm{H} / \mathrm{L}$ and $\mathrm{Y} / \mathrm{X}$, resp.) and the untranslated region of exon 1 (at position +4 , variants $\mathrm{P} / \mathrm{Q}$ ) have been described. The first two (and possibly the third) influence gene expression and, in consequence, the serum concentration of the protein. The highest MBL level occurs in association with promoter genotype HYP/HYP, and the lowest with LXP/LXP homozygotes $[6,13-15]$.

\section{MBL-Dependent Complement Activation}

Until recently, MBL was believed to be the sole collectin able to activate the lectin pathway (LP) of complement. However, several reports indicate that $\mathrm{MBL}$ shares that property not only with ficolins (another family of collagenrelated lectins) but also with the so-called "novel collectins," like collectin 11 (CL-11 or collectin-kidney 1, CL-K1) and collectin 10 (CL-10 or collectin-liver 1, CL-L1) [17, 18]. After binding of the MBL-MASP complex to the target structure, conformational changes lead to the activation of MASPs which in consequence makes the cleavage of C4 and C2 possible and thus the initiation of the complement cascade. In spite of the different initiation mechanism, the lectin pathway resembles the classical pathway (CP), forming the same convertases for $\mathrm{C} 3$ and $\mathrm{C} 5$ components. Within the MASP family, three proteases (MASP-1, MASP-2, and MASP3) and two related, nonenzymatic proteins, MAp19 (sMAP) and MAp44 (MAP-1), have been identified. MASP-1, MASP3 , and MAp44 are the products of alternative splicing of the MASP1/3 gene while MASP-2 and MAp19 are synthesized under the control of the MASP2 gene [4, 19-21].

MASP-2 is believed to be the key enzyme responsible for LP activation as its proteolytic activity against C4 and C2 significantly exceeds the activity of $\mathrm{Cls}$, the corresponding element of the classical pathway $[4,19,22]$. MASP-1 was believed to upregulate lectin pathway activation. However, recently, its crucial role in MASP-2 activation has been postulated [23-25]. MASP-3 and nonenzymatic proteins are believed to play a regulatory role in this process [19, 26-28]. A schematic overview of LP activation is presented in Figure 1.

\section{Involvement of MBL-Associated Serine Proteases in Coagulation and Kallikrein-Kinin Systems}

The increased infection susceptibility of MBL-deficient individuals is now well documented by numerous laboratory and clinical data but its description is outside the scope of this review. Recent studies bring an increasing amount of evidence that MBL plays an important role in other systemic processes including coagulation, inflammation, and tissue injury.

MASP-1 and -2 may participate in activation of the coagulation system. The former is able to cleave fibrinogen, factor XIII, and thrombin-activatable fibrinolysis inhibitor (TAFI) [29-34] while MASP-2 is able to cleave prothrombin [32]. Moreover, Megyeri et al. [35] found MASP-1 to interact with protease-activated receptor-4, a mediator of inflammation and platelet activation. Later, Dobó et al. [36] found high-molecular-weight kininogen to be its additional substrate. This activity (like that of kallikrein) enables release of bradykinin, a highly proinflammatory mediator of the kinin-kallikrein system. Although MASP-2 cleaves kininogen as well, no bradykinin is released during this process [36].

The contribution of MASPs to fibrin clot formation on the surface of pathogens may limit dissemination of infection [32]. The involvement of MBL-MASP complexes in haemostatic processes was later demonstrated in an animal model by Takahashi et al. [33] who found that MBL-null mice infected with Staphylococcus aureus were predisposed to the development of disseminated intravascular coagulation (DIC). Moreover, MBL- and MASP-1/3- (but not MASP-2- or C3-) null mice had prolonged bleeding time after injury [33]. 


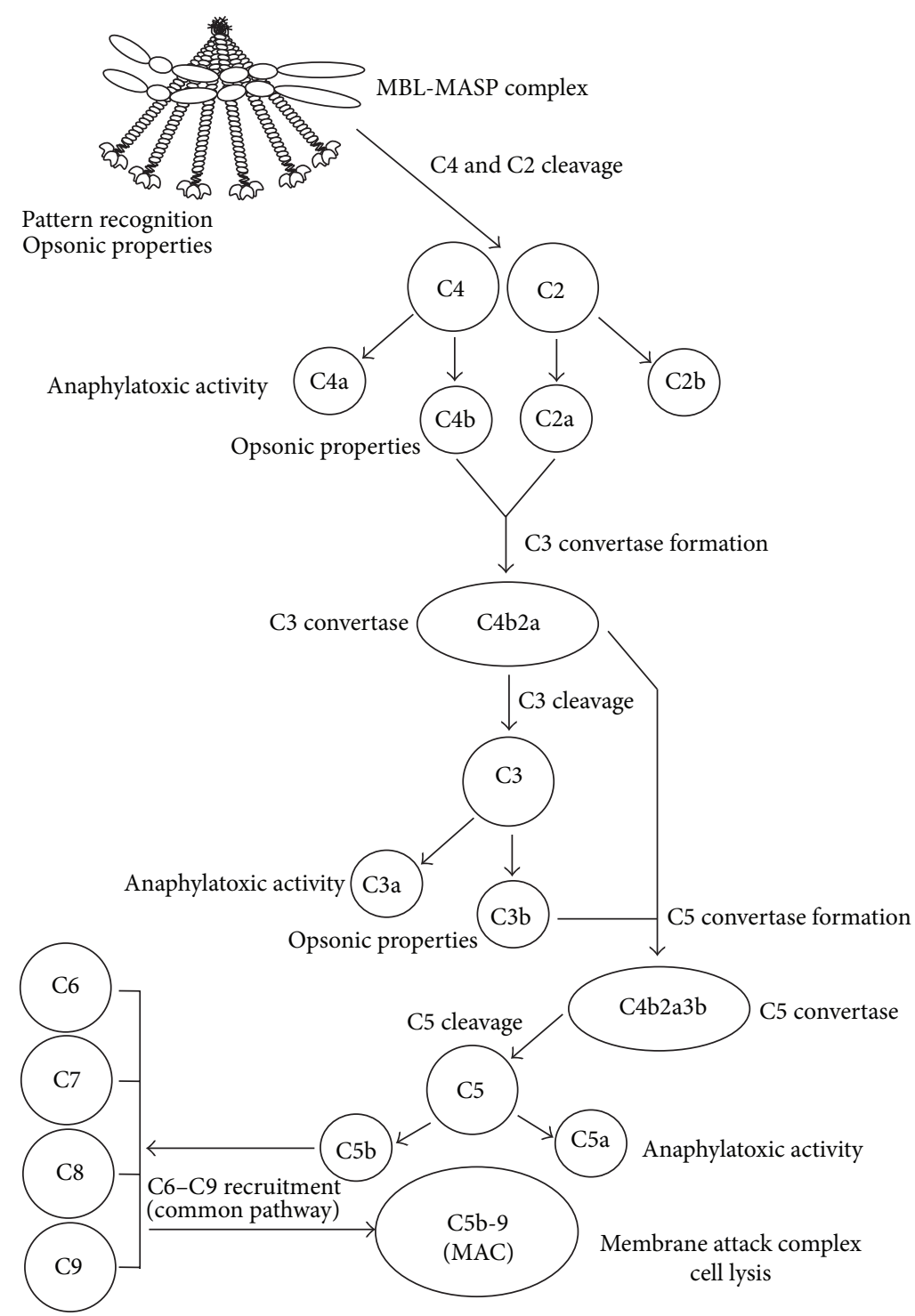

FIGURE 1: Schematic overview of MBL-dependent activation of the lectin pathway of complement. Modified from [5]. Scheme of MBL-MASP complex based on [23].

\section{MBL in Injury to Peripheral Organs}

The impact of components of the lectin pathway (especially $\mathrm{MBL}$ ) on both systemic inflammation and peripheral organ injury has been extensively investigated. These studies, concerning various clinical conditions, often lead to contradictory conclusions, proving not for the first time that the innate immune response is a "double-edge sword," sometimes beneficial and at other times disastrous for the host. MBL and MBL-dependent complement activation have been found to be involved in ischaemia-reperfusion (I/R) injury associated with numerous clinical conditions such as graft (kidney, lung) rejection and other pathological processes in the gastrointestinal tract or central nervous system.

4.1. Kidney Injury. Significant deposition of MBL-MASP2 complexes was found in porcine kidney after I/R injury.
Moreover, colocalization of C4d with MBL (as with C1q) was observed [37]. Administration of $\mathrm{Cl}$ esterase inhibitor (C1INH) resulted in inhibition of apoptosis of tubular epithelial cells and tubular damage. Therefore, a pathogenic role of both lectin and classical pathways in I/R renal injury was implicated. Møller-Kristensen et al. [38] found that MBLdouble knockout (lacking both MBL-A and -C) mice were protected from experimental renal ischaemia-reperfusion damage. Reconstitution with recombinant human MBL led to kidney injury, in a dose-dependent manner. These authors demonstrated involvement of complement activation in this process. Earlier, de Vries et al. [39] found colocalization of MBL with complement factor $\mathrm{C} 6$ in the later reperfusion phase. However, contradictory results have recently been published by Miwa et al. [40], who, after crossing decayaccelerating factor (DAF, CD55) and CD59 double knockout 
mice with animals deficient with various complement components/receptors, demonstrated a crucial role for the alternative but not the classical or lectin pathways. Furthermore, van der Pol et al. [41], using another rodent (rat) model, suggested that, although MBL took part in kidney dysfunction, it was not associated with complement activation. In their study, therapeutic inhibition of MBL was protective against tubular damage, preventing accumulation of macrophages and neutrophils as well as expression of proinflammatory cytokines and chemokines. Following reperfusion, MBL was internalized into tubular epithelial cells, inducing rapid cell death. Therefore, it was concluded that MBL-mediated (but lectin pathway-independent) cytotoxicity preceded complement activation and was the primary reason for tubular injury. Interestingly, a similar effect was demonstrated on human epithelial cells in vitro [41].

MBL deposition in ischaemically injured human kidney was first reported by de Vries et al. [39]. It appeared early after transplantation, in peritubular capillaries and tubular epithelial cells. Berger et al. demonstrated a beneficial effect of low (<400 ng/mL) serum MBL concentrations and "low MBL" variants $(\mathrm{XA} / \mathrm{O}, \mathrm{O} / \mathrm{O})$ of the corresponding gene in recipients of kidney or combined pancreas-kidney transplants on graft and patient survival. Low levels of circulating MBL correlated with improved long-term graft survival $[42,43]$. In contrast, Bay et al. [44] found the 5-year death-censored renal graft survival to be lower in MBL-deficient patients. In other reports, no impact of polymorphisms of the $M B L 2$ gene in recipients [45] or of $M B L 2, M A S P 2$, and FCN2 genes (the last mentioned one is responsible for synthesis of another lectin pathway activating molecule, ficolin-2) in either donors or recipients [46] on kidney transplant outcome was observed. Such contradictory results might reflect a dual role of MBL in renal transplantation. Damman and Seelen [47] suggested that under moderate graft injury, lectin pathway activation may be beneficial due to participation in the clearance of dying cells. However, under severe injury, MBL might contribute to the renal tubular epithelium damage.

According to Osthoff et al. [48], MBL deficiency could offer some protection from $\mathrm{I} / \mathrm{R}$ radiocontrast-induced kidney injury. In patients with serum MBL levels $<500 \mathrm{ng} / \mathrm{mL}$, they observed less organ dysfunction.

4.2. Cerebral Ischaemia. Several reports demonstrated an association of MBL with cerebral ischaemia. Ducruet et al. [49] observed deposition of MBL (both A and C forms) in murine ischaemic endothelium. In double knockout mice, C3 activation and subacute accumulation of mononuclear cells in the ischaemic region were absent. However, despite improved outcome within one day, the neuroprotective effect was not sustained. Morrison et al. [50] found a beneficial effect of MBL deficiency in striatum only. Even in MBL-null mice, they observed C3 deposition in the hemisphere, during reperfusion, suggesting involvement of other complement activation pathways in the pathology. Later, Orsini et al. [51], working with mice, confirmed MBL deposition in ischaemic vessels and a protective effect of genetically determined MBL deficiency; they also found an increase in circulating MBLMASP-2 complex concentration. Moreover, a long-lasting protective effect of anti-MBL-A antibody and synthetic MBL inhibitor in rats was noted [51]. Elvington et al. [52] did not detect C3d deposition in Clq- and MBL-deficient mice and found them to be protected from experimental I/R injury. These authors also demonstrated involvement of the third (alternative) pathway of complement activation. Interestingly, C6 deficiency had no effect, indicating the lack of significance of the common pathway and thus forming of the MAC.

Cervera et al. [53] provided data from both animal and clinical studies. The authors induced brain ischaemia by 2-hour occlusion of the middle cerebral artery in MBLnull and wild-type mice (control). MBL-null mice presented smaller infarctions, better functional outcome, and diminished C3 deposition and neutrophil infiltration. However, animals that received recombinant human $\mathrm{MBL}$ showed significantly larger areas of infarction. In the clinical study, an unfavourable outcome in stroke patients (109 ischaemic, 24 haemorrhagic) after 3 months was associated with MBLsufficient genotypes and higher circulating MBL levels. Based on both studies, the authors concluded that genetically determined MBL deficiency is associated with a better outcome after acute stroke.

Similar results were obtained by Osthoff et al. [54] who determined MBL concentrations in 353 consecutive patients with ischaemic stroke, of whom 287 received conservative while 66 received thrombolytic treatment. Within the latter group, additional samples were analyzed 24 and 72 hours after admission. In the conservatively treated group, with mild strokes, small infarction volume and favorable outcomes after three months demonstrated 1.5-2.6-fold lower median MBL levels compared with patients with more severe strokes. MBLdeficient patients $(<100 \mathrm{ng} / \mathrm{mL}$ ) had significantly lower risk of unfavorable outcome and showed smaller lesion volumes. In the thrombolysis group no association of MBL concentration with infarction volume or functional outcome was found. The authors suggested that inhibition of lectin pathway may be a promising strategy for reducing I/R associated cerebral damage.

In a recent clinical study Wang et al. [55] assessed serum levels of MBL in 148 Chinese patients with acute ischaemic stroke (the blood samples were obtained within 24 hours from recognition). MBL levels were significantly higher in stroke patients compared with healthy controls and increased with increasing severity of stroke. The authors postulated that elevated MBL levels could be an independent stroke risk factor in the Chinese population. However, no data concerning $M B L 2$ genotypes were provided.

4.3. Lung Transplantation. Several papers have focused on the role of MBL in lung transplantation. Its higher levels in plasma of recipients were associated with development of bronchiolitis obliterans syndrome (BOS) and poorer longterm outcome $[56,57]$. Immunohistochemistry revealed the presence of MBL in lung tissue from patients with BOS and at the time of ischaemia [57]. Moreover, Carroll et al. [58] 
observed a significant increase of $\mathrm{MBL}$ concentration in plasma at 3, 6, and 12 months after transplantation. Interestingly, the presence of MBL in bronchoalveolar lavage (BAL) (3 and 6 months after transplant) was associated with later BOS development [58]. In contrast, Hodge et al. [57] found no correlation between blood MBL levels and time after transplantation. They found lower MBL concentrations in BAL from recipients who developed BOS, in comparison with controls and patients with stable graft function. In another study, Kwakkel-van Erp et al. [59] did not report any impact of MBL levels on BOS but they noted a significant decrease of serum MBL after transplantation. Low MBL concentrations were, however, associated with a longer survival. Earlier, Munster et al. [60] postulated a beneficial effect of donor's MBL2 X gene variant (promoter, position -221) on lung transplant outcome (better graft and BOS-free survival). However, carrying the same allele in hepatitis- $C$ virus- (HCV-) positive recipients of liver transplants was a risk factor for acute cellular rejection [61].

4.4. Gastrointestinal Ischaemia. Interesting data have been provided concerning I/R damage in the gastrointestinal tract on mice model. Zhang et al. [62] found that IgM, bound to antigens in ischaemic mesenterium, provided a binding site for $\mathrm{MBL}$ resulting in complement activation. This finding was further confirmed by Lee et al. [63] who detected MBL (as well as C1q) complexed to antigen and natural IgM in the intestinal I/R injury model. They, moreover, excluded any involvement of the alternative pathway. That seems to be in agreement with results published by Busche et al. [64], concerning myocardial infarction (see below). Later, Schwaeble et al. [65] postulated MASP-2 deficiency to protect mice from gastrointestinal ischaemia-reperfusion damage.

\section{MBL in Cardiovascular Disease}

5.1. MBL in Cardiac Ischaemia-Reperfusion Injury. Involvement of $\mathrm{MBL}$ in coagulation and ischaemia-reperfusion (I/R) injury is potentially harmful in the development of cardiovascular disease, especially coronary artery disease and myocardial infarction (MI), as well as in the rejection of a heart transplant.

As coronary artery disease (leading to myocardial infarction) is the leading cause of morbidity and mortality worldwide, one of the therapeutic challenges of modern cardiology is to create a strategy to reduce the area of infarction and improve cardiac repair after MI. That is why research continues into the mechanisms of cardiac ischaemia-reperfusion injury and possibilities of interventions. Ischaemia changes expression of surface molecules and leads to formation of neoantigens. Paradoxically, reperfusion causes a harmful inflammatory response that can counteract the beneficial effects of improved blood flow. During reperfusion, myocardial cells become the targets of innate immunity: promoting release of inflammatory mediators, neutrophil recruitment, oxidative stress, complement, and TLR activation [66].
5.1.1. Data from Animal Models. The possible impact of lectin pathway factors on myocardial ischaemic injury was first demonstrated by Collard et al. [67] who observed MBL deposition in ischaemic rodent heart. Their in vitro experiments proved moreover that endothelial iC3b deposition after oxidative stress was attenuated by MBL ligands (as $\mathrm{N}$-acetyl-D-glucosamine or D-mannose) as well as in MBL-deficient serum. Later, Jordan et al. [68] showed that the blocking of MBL-dependent LP activation reduced the extent of myocardial ischaemia-reperfusion injury in rats. Furthermore, Walsh et al. [69] found that MBL-deficient mice were protected from cardiac ischaemic injury. In contrast, in animals lacking $\mathrm{Clq}$ (but with intact $\mathrm{MBL}$ ), no protective effect was noted. The importance of the lectin pathway was confirmed by Schwaeble et al. [65] who demonstrated that MASP-2-deficient, but not C4-deficient, mice had a significant reduction in myocardial infarct size. That moreover suggested that LP may be activated via C4-by-pass, as LPmediated C3 activation required MASP-2, MASP-1/3, and C2. Recently, Pavlov et al. [70] showed that inhibition of the lectin pathway using MAP-1 (MAp44) preserved cardiac function, decreased infarct volume, decreased C3 and MBL deposition, and prevented thrombogenesis.

An interesting insight into the mechanisms causing myocardial ischaemia-reperfusion $(\mathrm{MI} / \mathrm{R})$ injury was provided by Busche et al. [64]. Using MBL-A-, MBL-C-, and secreted IgM-null mice, they found that myocardial tissue injury following $\mathrm{MI} / \mathrm{R}$, associated with complement activation, depended on both MBL and IgM antibodies. That seems to be in agreement with the results published by Zhang et al. [62] and Lee et al. [63], concerning gastrointestinal IR previously mentioned. Earlier, the same group suggested $\mathrm{MBL}$ played a critical role in $\mathrm{MI} / \mathrm{R}$ connected with diabetes [71].

5.1.2. Clinical Data. As in experimental animal models, the role of MBL in cardiovascular disease has been investigated in clinical settings. Pesonen et al. [72] found lower serum concentrations of $\mathrm{C} 3$, higher levels of $\mathrm{MBL}$, and a higher frequency of high MBL level-associated MBL2 genotypes in a cohort of patients with unstable angina pectoris or acute myocardial infarction compared with healthy controls. Similarly, Haahr-Pedersen et al. [73] observed significantly higher MBL and lower soluble C5b-9 (complement membrane attack complex, MAC) concentrations in sera of patients with ST-elevation myocardial infarction (STEMI), undergoing primary percutaneous coronary intervention with left ventricular ejection fraction (LVEF) $<35 \%$ compared with those with LVEF $\geq 35 \%$. Interestingly, Keller et al. [74] noted that an elevated MBL level is a risk factor for future development of coronary artery disease (CAD) in apparently healthy men but not in women. Recently, Schoos et al. [75] have found high plasma levels of MBL and ficolin-2 (L-ficolin) to be synergistically associated with increased postinfarct left ventricular end systolic and diastolic volumes (ESV, EDV) in STEMI patients. Correspondingly, Trendelenburg et al. [76] reported that MBL functional deficiency (defined as serum concentration $\leq 100 \mathrm{ng} / \mathrm{mL}$ ) contributed to the significant 
reduction of 90-day mortality in patients with acute STEMI, undergoing early reperfusion by catheter revascularization. On the other hand, no association of low MBL with combined endpoint of death, development of shock and congestive heart failure, or laboratory markers of ischaemia (kinase creatinine CK and CK-MB levels) was observed. As the main cause of patients' death was fatal cardiac arrhythmia, the authors speculated that MBL deficiency did not affect the size of infarction but might influence the risk of arrhythmia [76]. Bilgin et al. [77] found that MBL-deficient (serum concentration $\leq 80 \mathrm{ng} / \mathrm{mL}$ ) patients with sterile systemic inflammation (systemic inflammatory response syndrome, SIRS) after cardiac surgery did not develop multiple organ failure (MOF) unless MBL was reconstituted by transfusion of fresh frozen plasma. Later, it was hypothesized (although based on data from one person) that postoperatively transfused MBL in MBL-deficient individuals (an increment of serum level from $<1 \mathrm{ng} / \mathrm{mL}$ up to nearly $400 \mathrm{ng} / \mathrm{mL}$ ) with acute myocardial infarction might result in a fatal outcome [78]. Recently, Holt et al. [79] demonstrated higher plasma concentrations of MASP1/3 gene products (MAp44, MASP-1, and MASP-3) to be higher in patients with MI compared to healthy controls. That was, however, not associated with short-term outcome (salvage index, final infarct).

Several reports, however, provide opposite findings. A clinical prospective study by Saevarsdottir et al. [80] recruited more than 19000 participants and estimated the risk of myocardial infarction in relation to $\mathrm{MBL}$ concentration. The influence of such factors as sex, age, diabetes, hypercholesterolemia, hypertension, smoking, and elevated erythrocyte sedimentation rate (ESR) was taken into consideration as well. MBL levels $>1 \mu \mathrm{g} / \mathrm{mL}$ (defined by authors as "high") were associated with decreased risk of MI, independently of other factors. Further analysis of data from the randomly selected nested case-control sample ( $>1300$ persons) revealed that higher MBL markedly decreased MI risk in individuals with diabetes, hypercholesterolemia, or raised ESR (but not in smokers or hypertensive patients). Moreover, there was no difference in a risk of infarction between diabetic and nondiabetic patients having MBL concentrations $>1 \mu \mathrm{g} / \mathrm{mL}$ [80]. These results seem to be in agreement with data published by Vengen et al. [81] who found that possession of $\mathrm{MBL}$ deficiency-associated genotypes $(\mathrm{XA} / \mathrm{O}, \mathrm{O} / \mathrm{O})$ was associated with double the incidence of $\mathrm{MI}$ at middle age (29-62 yrs). Such MBL2 gene variants as well as low plasma concentrations of its product were associated with increased frequency of significant artery stenosis. Again, MBL deficiency happened to be the risk factor independent of "conventional" risk factors. Single nucleotide polymorphisms (SNPs) of genes for ficolins did not influence the risk of myocardial infarction.

Mellbin et al. [82] reported the distribution of $M B L 2$ gene variant alleles in patients suffering from type 2 diabetes and MI, to be similar to that in the general population. No greater impact of the genotype or corresponding phenotype on the risk of infarction was noted. However, MBL concentration below average in "low-coding MBL genotype" (defined as $\mathrm{XA} / \mathrm{XA}, \mathrm{A} / \mathrm{O}$, or $\mathrm{O} / \mathrm{O}$ ) carriers was suggested to be disadvantageous.
5.2. MBL and Chronic Coronary Artery Disease. Numerous papers refer to clinical and experimental studies evaluating the role of $\mathrm{MBL}$ in the development of chronic coronary artery disease. Matthijsen et al. [83] found the deposition of MBL but not enhanced gene expression in human ruptured atherosclerotic lesions. They moreover observed that lowdensity lipoprotein receptor-null mice with MBL-A- and MBL-C-deficient monocytic cells, fed on a high-cholesterol diet, were more likely to develop atherosclerotic lesions than their MBL-A, $-\mathrm{C}(+/+)$ counterparts. That could be caused by reduced removal of apoptotic cells and cellular debris in the absence of MBL. Oral fat loading tests in volunteers showed MBL-deficient individuals $(<0.42 \mu \mathrm{g} \mathrm{MBL}$ per $\mathrm{mL}$ of serum, determined in a functional hemolytic assay) to have higher postprandial lipid values (contributing to the development of atherosclerosis) in comparison with MBL-sufficient controls [84].

The development of atherosclerosis is known to be associated with Chlamydia pneumoniae infection. The presence of this microorganism within atheroma has been reported in several studies [85-91]. Involvement of MBL in host defense against Chlamydia was originally suggested by Swanson et al. [90], based on inhibition of infection of cell cultures by various bacterial strains with recombinant lectin. Further, Rugonfalvi-Kiss et al. [91] suggested that carriage of O MBL2 alleles may be associated with development and progression of severe coronary artery disease in C. pneumoniae-infected individuals. The role of $\mathrm{MBL}$ in pathophysiology of cardiovascular disease in Danish patients with rheumatoid arthritis was considered by Troelsen et al. [92, 93]. They found that high serum MBL concentrations and "high MBL producing" genotypes contributed significantly to the risk of ischaemic heart disease, myocardial infarction, overall death, and death due to cardiovascular disease [92, 93]. Data from patients with Kawasaki disease suggest that the impact of MBL2 polymorphism may be age dependent: children younger than 1 year with variant alleles were at higher risk of development of coronary artery lesions than those without, while among older children, the relationship was the opposite $[94,95]$.

Data reviewed in this section demonstrate that the influence of MBL on the development of cardiovascular disease and/or prognosis for patients is complex. MBL and activation of the lectin pathway of complement may be protective against the development of atherosclerotic lesions by clearance of apoptotic cells and cell debris from atherosclerotic plaques or by protection from Chlamydia pneumoniae infection. On the other hand, MBL may take part in I/R injury processes and enhance thrombosis. In consequence, its resultant effect may depend on diverse factors, specific for the individual, including accompanying diseases, life style, age, and sex. The importance of MBL-dependent mechanisms is still not fully understood. The ambiguous role of MBL in the development of coronary artery lesions and myocardial infarction is presented in Figure 2.

5.3. MBL and Heart Transplantation. Similarly, contradictory results concerning the role of $\mathrm{MBL}$ in heart transplantation have been published. The long-term success of heart 
Mannan-binding lectin

\begin{tabular}{|c|c|}
\hline Protective & Harmful? \\
\hline $\begin{array}{l}\text { Atherosclerosis } \\
\text { - Protection from infection } \\
\text { - Clearance of cellular debris and apoptotic cells }\end{array}$ & $\begin{array}{l}\text { Ischaemia-reperfusion injury }\} \\
\text { - Enhancement of thrombosis } \\
\text { - Complement-mediated injury }\end{array}$ \\
\hline $\begin{array}{l}\text { Risk of coronary artery lesions in Kawasaki } \\
\text { disease (children }<1 \text { year old) } \\
\text { - Protection from infection? }\end{array}$ & \\
\hline
\end{tabular}

FIGURE 2: Ambiguous role of mannan-binding lectin in the development of coronary artery disease and myocardial infarction. Based on data reviewed in Section 5.

transplantation is limited by the development of cardiac allograft vasculopathy (CAV). CAV is characterized by diffuse and concentric narrowing of the coronary arteries as a result of neointimal expansion that is often accompanied by adventitial fibrosis. It remains one of the major causes of death after transplantation, although the pathogenesis is still not fully understood. A key feature is the development of donor-specific antibodies against human leukocyte antigens (HLA). The severity of CAV correlates with persistent inflammation and a higher degree of HLA mismatch [9698]. Although immunosuppressive drugs permit successful heart transplantation, they do not always prevent chronic rejection. Innate immune responses like infiltration by $\mathrm{NK}$ cells, activation of Toll-like receptors (TLR), and complement deposition are known to participate in the acute rejection of cardiac allografts and in the development of CAV [98]. The involvement of complement in graft rejection was first suggested in 1999, when Baldwin et al. found deposition of C4d and C3 in a series of cardiac biopsy specimens in the first weeks after transplantation and demonstrated that this deposition was associated with the peritransplant ischaemic injury [99]. However, the role of MBL and lectin pathway activation has not been fully elucidated. Fiane et al. [100] showed MBL deficiency (serum level $<0.1 \mu \mathrm{g} / \mathrm{mL}$ ) to be related to the development of graft-associated coronary artery disease (GACD) and acute rejection episodes after heart transplantation. However, higher complement activity was found in patients with ischaemia (C4bc level reflecting lectin and classical pathways). As there were no differences in concentrations of classical pathway serine proteases $\mathrm{Clr} / \mathrm{C} 1 \mathrm{~s}$ complexed with C1-inhibitor (C1-INH), the authors postulated that the lectin pathway may play a leading role. Moreover, the soluble terminal complex, resulting from all three pathways, correlated with mortality. Later, Fildes et al. [101] did not observe an association of MBL concentrations and GACD, but they reported less acute graft rejection episodes in MBL-deficient patients.

5.4. Therapeutic Complement Inhibition in Cardiovascular Disease. Since the role of complement in the pathophysiology of cardiovascular disease (atherosclerosis, myocardial infarction, heart transplant rejection, cardiac surgery complications) was established, a series of studies evaluating the benefits of complement inhibition has been conducted. Apart from the above-mentioned experimental studies employing anti-MBL [67, 68] or anti-MASP-2 antibodies [65], the selective inhibition of the initial steps of the lectin pathway has not been fully investigated and lacks clinical evaluation. Rather, the attention has been turned to a potent complement inhibitor, C1-INH, widely used in the treatment of hereditary angioedema. $\mathrm{Cl}-\mathrm{INH}$ is an acute phase protein, belonging to the serpins, a superfamily of serine protease inhibitors. It has a wide range of biological functions: interacts with coagulation/fibrinolysis and contact systems (inactivates factors XII, XI, thrombin, plasmin, tissue plasminogen activator, and kallikrein), extracellular matrix, circulating neutrophils and macrophages (enhances phagocytosis), endothelial cells (inhibits leukocyte adhesion), infectious agents (bacteria: Escherichia coli, Bordetella pertussis; parasites: Plasmodium falciparum), and endotoxins (from Salmonella typhimurium) and inhibits all pathways of complement activation [102, 103]. It is known to inactivate $\mathrm{Clr}$ and Cls (classical pathway) as well as MASP-1 and MASP-2 (lectin pathway). Moreover, C1INH in vitro influences the alternative pathway via reversible binding to $\mathrm{C} 3 \mathrm{~b}$, thus interfering with $\mathrm{C} 3 \mathrm{~b}$-factor $\mathrm{B}$ interactions $[104,105]$.

Since the 1990s, several studies have been published, proving successful use of C1-INH in animal models of myocardial injury. Buerke et al. [106] tested the cardioprotective effect of C1-INH in a feline model of myocardial I/R. C1-INH administration $10 \mathrm{~min}$ prior to reperfusion improved recovery of cardiac contractility, decreased leukocyte accumulation, preserved coronary vascular endothelial function, and decreased the amount of necrotic tissue, compared with controls. Six years later, the same group carried out a similar study, using a novel small molecule C1s-inhibitor in a rabbit model of myocardial ischaemia-reperfusion injury that yielded similar conclusions [107]. In Horstick's et al. study, intracoronary application of $\mathrm{C1}$-INH reduced myocardial damage in a porcine model of myocardial ischaemia (60 min of coronary occlusion followed by $2 \mathrm{~h}$ of reperfusion) [108]. The same authors paid attention to the importance of properly adjusted dosage of C1-INH [109]. Using the same animal model, they found that administration of $40 \mathrm{IU}$ of an inhibitor per $\mathrm{kg}$ reduced myocardial injury; $100 \mathrm{IU} / \mathrm{kg}$ did not offer beneficial effects while a large dose $(200 \mathrm{IU} / \mathrm{kg})$ provoked side effects and coagulation disorders. In contrast, Schreiber et al. [110] found no influence of C1-INH on the area of infarction or ventricular function in a porcine model. 
TABLE 1: Major associations of mannan-binding lectin with myocardial infarction in humans.

\begin{tabular}{llc}
\hline Suggested MBL effect & Clinical association & Reference \\
\hline & "High MBL" genotypes more frequent and higher levels of MBL in sera of patients & Pesonen et al. [72] \\
with acute MI compared to controls & & \\
Harmful & Higher levels in patients with STEMI and LVEDF <35\% comparing to controls with & Haahr-Pedersen et al. [73] \\
& STEMI and LVEDF >35\% & Schoos et al. [75] \\
& High serum levels associated with increased postinfarct ventricular ESV and EDV & Trendelenburg et al. [76] \\
\hline in STEMI patients & Low serum levels associated with lower mortality & Saevarsdottir et al. [80] \\
Protective & High serum level associated with decreased risk of MI & Vengen et al. [81] \\
\hline
\end{tabular}

The beneficial role of C1-INH in limiting ischaemiareperfusion injury probably is not only the consequence of complement inhibition. Administration of C1-INH in a rat model of MI [111] improved cardiac function and reduced myocardial infarct size due to the inhibition of complement activation and leukocyte recruitment (due to lower expression of the endothelial adhesion molecules, P-selectin, and intercellular adhesion molecule 1 (ICAM-1). Higher doses $(100 \mathrm{IU} / \mathrm{kg})$ of C1-INH led to prolonged beneficial effects in comparison with lower (10 or $50 \mathrm{IU} / \mathrm{kg}$ ) doses. In a recent study by Lu et al. [112], C1-INH-deficient, C3-deficient, and wild-type mice were subjected to coronary artery occlusion (left anterior descending branch) and subsequent reperfusion. C1-INH was administered prior to reperfusion. Besides the cardioprotective effect of C1-INH, a decrease in neutrophil accumulation was observed compared with vehicletreated animals. This finding seems to confirm the contribution of C1-INH to inhibition of leukocyte recruitment into ischaemic tissue. Another postulated beneficial effect of C1-INH administration after I/R injury is its antiapoptotic activity. In a rat model of MI, C1-INH caused the reversal of the Bcl-2/Bax expression in the myocardial infarct area [113].

Encouraging animal experiences led to clinical application of C1-INH in cardiac disease. In 1998 Bauernschmitt et al. [114] presented their first experiences with C1-INH as a rescue therapy in three patients undergoing emergency surgical revascularization, after failed percutaneous coronary angioplasty, and achieved rapid restoration of myocardial function during reperfusion. In 2002 de Zwann et al. [115] showed that an intravenous bolus followed by an infusion of C1-INH given 6 hours after myocardial infarction in 22 patients caused reduction in levels of CK-MB, troponin $\mathrm{T}$, and circulating $\mathrm{C} 4$ fragments. Thielmann et al. [116] studied the effects of C1-INH in patients undergoing emergency coronary artery bypass grafting after acute STelevation myocardial infarction. Cardiac troponin I levels were markedly reduced in the study group $(n=29)$, given two C1-INH doses (40 IU/kg during reperfusion and $20 \mathrm{IU} / \mathrm{kg}$, $6 \mathrm{~h}$ after surgery), compared with the controls $(n=28)$. Similar results were reported by Fattouch et al. [117], in a larger group of patients (38 persons treated with two doses of $500 \mathrm{IU}$ each, first given before reperfusion, followed by the second, $3 \mathrm{~h}$ after surgical intervention, and 28 persons receiving placebo). Despite these promising findings, $\mathrm{C} 1-\mathrm{INH}$ will not be accepted for clinical practice unless it is confirmed by multicenter, randomized trials.

Inhibitors of later stages of complement activation, such as pexelizumab (anti-C5 monoclonal antibody) or TP10 (soluble derivative of human complement receptor type 1 (CR-1), accelerating the decay of $\mathrm{C} 3$ and $\mathrm{C} 5$ convertases through proteolytic degradation of $\mathrm{C} 3 \mathrm{~b}$ and $\mathrm{C} 4 \mathrm{~b}$ ) were evaluated in both animal models and clinical trials involving patients after coronary artery bypass graft (CABG) surgery [118-125]. Some benefit was observed in a small group of patients but the primary endpoints were not met in large clinical trials. Description of these studies lies outside the scope of this review.

\section{Summary and Conclusion}

The involvement of complement activation in the pathogenesis of cardiovascular disease and ischaemia-reperfusion injury in general is well documented. However, the role of $\mathrm{MBL}$ and the lectin pathway cannot be unequivocally defined, as published data points to opposite and sometimes confusing conclusions (Table 1). It should be remembered that MBL is just one component of the complicated network of complex mechanisms involving host and environmental factors. That is probably the reason why the attempts to influence complement activity therapeutically, although often promising, are still not fully successful.

\section{Conflict of Interests}

The authors declare that there is no conflict of interests regarding the publication of this paper.

\section{Authors' Contribution}

Izabela Pągowska-Klimek and Maciej Cedzyński contributed equally to this paper.

\section{Acknowledgments}

This work was supported by the Polish National Science Centre, Grant no. UMO-2011/03/B/NZ6/00052. The authors thank Dr. D. C. Kilpatrick for critical reading of the paper and editorial suggestions. 


\section{References}

[1] M. W. Turner, "Mannose-binding lectin: the pluripotent molecule of the innate immune system," Immunology Today, vol. 17, no. 11, pp. 532-540, 1996.

[2] D. C. Kilpatrick, "Mannan-binding lectin and its role in innate immunity," Transfusion Medicine, vol. 12, no. 6, pp. 335-352, 2002.

[3] U. Holmskov, S. Thiel, and J. C. Jensenius, "Collectins and ficolins: humoral lectins of the innate immune defense," Annual Review of Immunology, vol. 21, pp. 547-578, 2003.

[4] S. Thiel, "Complement activating soluble pattern recognition molecules with collagen-like regions, mannan-binding lectin, ficolins and associated proteins," Molecular Immunology, vol. 44, no. 16, pp. 3875-3888, 2007.

[5] M. Cedzyński, A. S. Świerzko, and D. C. Kilpatrick, "Factors of the lectin pathway of complement associations in neonates," Journal of Biomedicine and Biotechnology, vol. 2012, Article ID 363246, 8 pages, 2012.

[6] A. S. Świerzko, D. C. Kilpatrick, and M. Cedzyński, "Mannan bindig lectin in malignancy," Molecular Immunology, vol. 55, no. 1, pp. 16-21, 2013.

[7] D. C. Kilpatrick, "Phospholipid-binding activity of human mannan-binding lectin," Immunology Letters, vol. 61, no. 2-3, pp. 191-195, 1998

[8] M. M. Estabrook, D. L. Jack, N. J. Klein, and G. A. Jarvis, "Mannose-binding lectin binds to two major outer membrane proteins, opacity protein and porin of Neisseria meningitidis," The Journal of Immunology, vol. 172, no. 6, pp. 3784-3792, 2004.

[9] A. J. Nauta, N. Raashou-Jensen, A. Roos et al., "Mannosebinding lectin engagement with late apoptotic and necrotic cells," European Journal of Immunology, vol. 33, no. 10, pp. 2853$2863,2003$.

[10] T. Hummelshoj, L. M. Fog, H. O. Madsen, R. B. Sim, and P. Garred, "Comparative study of the human ficolins reveals unique features of Ficolin-3 (Hakata antigen)," Molecular Immunology, vol. 45, no. 6, pp. 1623-1632, 2008.

[11] R. Wallis, "Interactions between mannose-binding lectin and MASPs during complement activation by the lectin pathway," Immunobiology, vol. 212, no. 4-5, pp. 289-299, 2007.

[12] J. S. Presanis, M. Kojima, and R. B. Sim, "Biochemistry and genetics of mannan-binding lectin (MBL)," Biochemical Society Transactions, vol. 31, no. 4, pp. 748-752, 2003.

[13] H. O. Madsen, P. Garred, S. Thiel et al., "Interplay between promoter and structural gene variants control basal serum level of mannan-binding protein," The Journal of Immunology, vol. 155, no. 6, pp. 3013-3020, 1995.

[14] D. C. Kilpatrick, "Clinical significance of mannan-binding lectin and L-ficolin," in Collagen-Related Lectins in Innate Immunity, D. Kilpatrick, Ed., pp. 57-84, Research Signpost, Trivandrum, India, 2007.

[15] S. Thiel and M. Gadjeva, "Humoral pattern recognition molecules: mannan-binding lectin and ficolins," Advances in Experimental Medicine and Biology, vol. 653, pp. 58-73, 2009.

[16] G. S. Butler, D. Sim, E. Tam, D. Devine, and C. M. Overall, "Mannose-binding lectin (MBL) mutants are susceptible to matrix metalloproteinase proteolysis. Potential role in human MBL deficiency," The Journal of Biological Chemistry, vol. 277, no. 20, pp. 17511-17519, 2002.

[17] Y. J. Ma, M. O. Skjoedt, and P. Garred, "Collectin-11/MASP complex formation triggers activation of the lectin complement pathway-the fifth lectin pathway initiation complex," Journal of Innate Immunity, vol. 5, no. 3, pp. 242-250, 2013.

[18] M. L. Henriksen, J. Brandt, J. P. Andrieu et al., "Heteromeric complexes of native collectin kidney 1 and collectin liver 1 are found in the circulation with MASPs and activate the complement system," The Journal of Immunology, vol. 191, pp. 6117-6127, 2013.

[19] R. Wallis, "Structural and functional aspects of complement activation by mannose-binding protein," Immunobiology, vol. 205, no. 4-5, pp. 433-445, 2002.

[20] S. E. Degn, A. G. Hansen, R. Steffensen, C. Jacobsen, J. C. Jensenius, and S. Thiel, "Map44, a human protein associated with pattern recognition molecules of the complement system and regulating the lectin pathway of complement activation," The Journal of Immunology, vol. 43, no. 12, pp. 1167-1178, 2009.

[21] M. Skjoedt, T. Hummelshoj, Y. Palarasah et al., "A novel mannose-binding lectin/ficolin-associated protein is highly expressed in heart and skeletal muscle tissues and inhibits complement activation," The Journal of Biological Chemistry, vol. 285, no. 11, pp. 8234-8243, 2010.

[22] V. Rossi, S. Cseh, I. Bally, N. M. Thielens, J. C. Jensenius, and G. J. Arlaud, "Substrate specificities of recombinant mannanbinding-associated serine proteases-1 and -2," The Journal of Biological Chemistry, vol. 276, no. 44, pp. 40880-40887, 2001.

[23] S. E. Degn, L. Jensen, A. G. Hansen et al., "Mannan-binding lectin-associated serine protease (MASP)-1 is crucial for lectin pathway activation in human serum, whereas neither MASP-1 nor MASP-3 is required for alternative pathway function," The Journal of Immunology, vol. 189, no. 8, pp. 3957-3969, 2012.

[24] D. Heja, A. Kocsis, J. Dobo et al., "Revised mechanism of complement lectin-pathway activation revealing the role of serine protease MASP-1 as the exclusive activator of MASP-2," Proceedings of the National Academy of Sciences of the United States of America, vol. 109, pp. 10498-10503, 2012.

[25] M. Megyeri, V. Harmat, B. Major et al., "Quantitative characterization of the activation steps of mannan-binding lectin (MBL)associated serine proteases (MASPs) points to the central role of MASP-1 in the initiation of complement lectin pathway," The Journal of Biological Chemistry, vol. 288, no. 13, pp. 8922-8934, 2013.

[26] C. Chen and R. Wallis, "Two mechanisms for mannose-binding protein modulation of the activity of its associated serine proteases," The Journal of Biological Chemistry, vol. 279, no. 25, pp. 26058-26065, 2004.

[27] T. Yongqing, N. Drentin, R. C. Duncan, L. C. Wijeyewickrema, and R. N. Pike, "Mannose-binding lectin serine proteases and associated proteins of the lectin pathway of complement: two genes, five proteins and many functions?" Biochimica et Biophysica Acta-Proteins and Proteomics, vol. 1824, no. 1, pp. 253-262, 2012.

[28] M. Matsushita, Y. Endo, and T. Fujita, "Structural and functional overview of the lectin complement pathway: its molecular basis and physiological implication," Archivum Immunologiae et Therapia Experimentalis, vol. 61, pp. 273-283, 2013.

[29] L. R. La Bonte, V. I. Pavlov, Y. S. Tan et al., "Mannose-binding lectin-associated serine protease- 1 is a significant contributor to coagulation in a murine model of occlusive thrombosis," The Journal of Immunology, vol. 188, no. 2, pp. 885-891, 2012.

[30] A. Krarup, K. C. Gulla, P. Gál, K. Hajela, and R. B. Sim, “The action of MBL-associated serine protease 1 (MASP1) on factor XIII and fibrinogen," Biochimica et Biophysica Acta-Proteins and Proteomics, vol. 1784, no. 9, pp. 1294-1300, 2008. 
[31] Y. Endo, N. Nakazawa, D. Iwaki, M. Takahashi, M. Matsushita, and T. Fujita, "Interactions of ficolin and mannose-binding lectin with fibrinogen/fibrin augment the lectin complement pathway," Journal of Innate Immunity, vol. 2, no. 1, pp. 33-42, 2009.

[32] K. C. Gulla, K. Gupta, A. Krarup et al., "Activation of mannanbinding lectin-associated serine proteases leads to generation of a fibrin clot," Immunology, vol. 129, no. 4, pp. 482-495, 2010.

[33] K. Takahashi, W. Chang, M. Takahashi et al., "Mannose-binding lectin and its associated proteases (MASPs) mediate coagulation and its deficiency is a risk factor in developing complications from infection, including disseminated intravascular coagulation," Immunobiology, vol. 216, no. 1-2, pp. 96-102, 2011.

[34] K. Hess, R. Ajjan, F. Phoenix, J. Dobó, P. Gál, and V. Schroeder, "Effects of MASP-1 of the complement system on activation of coagulation factors and plasma clot formation," PLoS ONE, vol. 7, no. 4, Article ID e35690, 2012.

[35] M. Megyeri, V. Makó, L. Beinrohr et al., "Complement protease MASP-1 activates human endothelial cells: PAR4 activation is a link between complement and endothelial function," The Journal of Immunology, vol. 183, no. 5, pp. 3409-3416, 2009.

[36] J. Dobó, B. Major, K. A. Kékesi et al., "Cleavage of Kininogen and subsequent Bradykinin release by the complement component: mannose-binding lectin-associated serine protease (MASP)-1," PLoS ONE, vol. 6, no. 5, Article ID e20036, 2011.

[37] G. Castellano, R. Melchiorre, A. Loverre et al., "Therapeutic targeting of classical and lectin pathways of complement protects from ischemia-reperfusion-induced renal damage," The American Journal of Pathology, vol. 176, no. 4, pp. 1648-1659, 2010.

[38] M. Møller-Kristensen, W. K. E. Ip, L. Shi et al., "Deficiency of mannose-binding lectin greatly increases susceptibility to postburn infection with Pseudomonas aeruginosa," The Journal of Immunology, vol. 176, no. 3, pp. 1769-1775, 2006.

[39] B. de Vries, S. J. Walter, C. J. Peutz-Kootstra, T. G. A. M. Wolfs, L. W. E. van Heurn, and W. A. Buurman, "The mannose-binding lectin-pathway is involved in complement activation in the course of renal ischemia-reperfusion injury," American Journal of Pathology, vol. 165, no. 5, pp. 1677-1688, 2004.

[40] T. Miwa, T. Sato, D. Gullipalli, M. Nangaku, and W. C. Song, "Blocking properdin, the alternative pathway, and anaphylatoxin receptors ameliorates renal ischemia-reperfusion injury in decay-accelerating factor and CD59 double-knockout mice," The Journal of Immunology, vol. 190, no. 7, pp. 3552-3559, 2013.

[41] P. van der Pol, N. Schlagwein, D. J. van Gijlswijk et al., "Mannan-binding lectin mediates renal ischemia/reperfusion injury independent of complement activation," American Journal of Transplantation, vol. 12, no. 4, pp. 877-887, 2012.

[42] S. P. Berger, A. Roos, M. J. K. Mallat, T. Fujita, J. W. de Fijter, and M. R. Daha, "Association between mannose-binding lectin levels and graft survival in kidney transplantation," American Journal of Transplantation, vol. 5, no. 6, pp. 1361-1366, 2005.

[43] S. P. Berger, A. Roos, M. J. K. Mallat et al., "Low pretransplantation mannose-binding lectin levels predict superior patient and graft survival after simultaneous pancreas-kidney transplantation," Journal of the American Society of Nephrology, vol. 18, no. 8, pp. 2416-2422, 2007.

[44] J. T. Bay, S. S. Sorensen, J. M. Hansen, H. O. Madsen, and P. Garred, "Low mannose-binding lectin serum levels are associated with reduced kidney graft survival," Kidney International, vol. 83, no. 2, pp. 264-271, 2013.
[45] Y. Gorgi, I. Sfar, H. Aouadi et al., "Mannose binding lectin (+54) exon 1 gene polymorphism in Tunisian kidney transplant patients," Transplantation Proceedings, vol. 41, no. 2, pp. $660-$ 662, 2009.

[46] J. Damman, J. L. Kok, H. Snieder et al., "Lectin complement pathway gene profile of the donor and recipient does not influence graft outcome after kidney transplantation," Molecular Immunology, vol. 50, no. 1-2, pp. 1-8, 2012.

[47] J. Damman and M. A. Seelen, "Mannan-binding lectin: a twofaced regulator of renal allograft injury?" Kidney International, no. 83, pp. 191-193, 2013.

[48] M. Osthoff, V. Piezzi, T. Klima et al., "Impact of mannosebinding lectin deficiency on radiocontrast-induced renal dysfunction: a post-hoc analysis of a multicenter randomized controlled trial," BMC Nephrology, vol. 13, article 99, 2012.

[49] A. F. Ducruet, S. A. Sosunov, B. E. Zacharia et al., "The neuroprotective effect of genetic mannose-binding lectin deficiency is not sustained in the sub-acute phase of stroke," Translational Stroke Research, vol. 2, no. 4, pp. 588-599, 2011.

[50] H. Morrison, J. Frye, G. Davis-Gorman et al., "The contribution of mannose binding lectin to reperfusion injury after ischemic stroke," Current Neurovascular Research, vol. 8, no. 1, pp. 52-63, 2011.

[51] F. Orsini, P. Villa, S. Parrella et al., "Targeting mannose-binding lectin confers long-lastin protection with a surprisingly wide therapeutic window in cerebral ischemia," Circulation, vol. 126, no. 12, pp. 1484-1494, 2012.

[52] A. Elvington, C. Atkinson, H. Zhu et al., "The alternative complement pathway propagates inflammation and injury in murine ischemic stroke," The Journal of Immunology, vol. 189, no. 9, pp. 4640-4647, 2012.

[53] A. Cervera, A. M. Planas, C. Justicia et al., "Geneticallydefined deficiency of mannose-binding lectin is associated with protection after experimental stroke in mice and outcome in human stroke," PLoS ONE, vol. 5, no. 2, Article ID e8433, 2010.

[54] M. Osthoff, M. Katan, F. Fluri et al., "Mannose-binding lectin deficiency is associated with smaller infarction size and favorable outcome in ischemic stroke patients," PLoS ONE, vol. 6, no. 6, Article ID e21338, 2011.

[55] Z. Y. Wang, Z. R. Sun, and L. M. Zhang, "The relationship between serum mannose-binding lectin levels and acute ischemic stroke risk," Neurochemical Research, vol. 39, no. 2, pp. 248-253, 2014.

[56] S. J. Budd, R. M. Aris, A. A. Medaiyese, S. L. Tilley, and I. P. Neuringer, "Increased plasma mannose binding lectin levels are associated with bronchiolitis obliterans after lung transplantation," Respiratory Research, vol. 13, article 56, 2012.

[57] S. Hodge, M. Dean, G. Hodge, M. Holmes, and P. N. Reynolds, "Decreased efferocytosis and mannose binding lectin in the airway in bronchiolitis obliterans syndrome," Journal of Heart and Lung Transplantation, vol. 30, no. 5, pp. 589-595, 2011.

[58] K. E. Carroll, M. M. Dean, S. L. Heatley et al., "High levels of mannose-binding lectin are associated with poor outcomes after lung transplantation," Transplantation, vol. 91, no. 9, pp. 1044-1049, 2011.

[59] J. M. Kwakkel-van Erp, A. W. M. Paantjens, D. A. van Kessel et al., "Mannose-binding lectin deficiency linked to cytomegalovirus (CMV) reactivation and survival in lung transplantation," Clinical and Experimental Immunology, vol. 165, no. 3, pp. 410-416, 2011.

[60] J. M. Munster, W. van der Bij, M. B. Breukink et al., "Association between donor MBL promoter haplotype and graft survival and 
the development of BOS after lung transplantation," Transplantation, vol. 86, no. 12, pp. 1857-1863, 2008.

[61] D. Eurich, S. Boas-Knoop, A. Yahyazadeh et al., "Role of mannose-binding lectin-2 polymorphism in the development of acute cellular rejection after transplantation for hepatitis C virus-induced liver disease," Transplant Infectious Disease, vol. 14, no. 5, pp. 488-495, 2012.

[62] M. Zhang, K. Takahashi, E. M. Alicot et al., "Activation of the lectin pathway by natural IgM in a model of ischemia/ reperfusion injury," The Journal of Immunology, vol. 177, no. 7, pp. 4727-4734, 2006.

[63] H. Lee, D. J. Green, L. Lai et al., "Early complement factors in the local tissue immunocomplex generated during intestinal ischemia/reperfusion injury," Molecular Immunology, vol. 47, no. 5, pp. 972-981, 2010.

[64] M. N. Busche, V. Pavlov, K. Takahashi, and G. L. Stahl, "Myocardial ischemia and reperfusion injury is dependent on both IgM and mannose-binding lectin," The American Journal of Physiology-Heart and Circulatory Physiology, vol. 297, no. 5, pp. H1853-H1859, 2009.

[65] W. J. Schwaeble, N. J. Lynch, J. E. Clark et al., "Targeting of mannan-binding lectin-associated serine protease2 confers protection from myocardial and gastrointestinal ischemia/reperfusion injury," Proceedings of the National Academy of Sciences of the United States of America, vol. 108, no. 18, pp. 7523-7528, 2011.

[66] L. Timmers, G. Pasterkamp, V. C. de Hoog, F. Arslan, Y. Appelman, and D. P. V. de Kleijn, "The innate immune response in reperfused myocardium," Cardiovascular Research, vol. 94, no. 2, pp. 276-283, 2012.

[67] C. D. Collard, A. Vakeva, M. A. Morrissey et al., "Complement activation after oxidative stress: role of the lectin complement pathway," The American Journal of Pathology, vol. 156, no. 5, pp. 1549-1556, 2000.

[68] J. E. Jordan, M. C. Montalto, and G. L. Stahl, "Inhibition of mannose-binding lectin reduces postischemic myocardial reperfusion injury," Circulation, vol. 104, no. 12, pp. 1413-1418, 2001.

[69] M. C. Walsh, T. Bourcier, K. Takahashi et al., "Mannosebinding lectin is a regulator of inflammation that accompanies myocardial ischemia and reperfusion injury," The Journal of Immunology, vol. 175, no. 1, pp. 541-546, 2005.

[70] V. Pavlov, M. O. Skjoedt, Y. S. Yan, and A. Rosbjerg, "Endogenous and natural complement inhibitor attenuates myocadial injury and arteria thrombogenesis," Circulation, vol. 126, no. 18, pp. 2227-2235, 2012.

[71] M. N. Busche, M. C. Walsh, M. E. McMullen, B. J. Guikema, and G. L. Stahl, "Mannose-binding lectin plays a critical role in myocardial ischaemia and reperfusion injury in a mouse model of diabetes," Diabetologia, vol. 51, no. 8, pp. 1544-1551, 2008.

[72] E. Pesonen, M. Hallman, S. Sarna et al., "Mannose-binding lectin as a risk factor for acute coronary syndromes," Annals of Medicine, vol. 41, no. 8, pp. 591-598, 2009.

[73] S. Haahr-Pedersen, M. Bjerre, A. Flyvbjerg et al., "Level of complement activity predicts cardiac dysfunction after acute myocardial infarction treated with primary percutaneous coronary intervention," Journal of Invasive Cardiology, vol. 21, no. 1, pp. 13-19, 2009.

[74] T. T. Keller, S. I. van Leuven, M. C. Meuwese et al., "Serum levels of mannose-binding lectin and the risk of future coronary artery disease in apparently healthy men and women," Arteriosclerosis, Thrombosis, and Vascular Biology, vol. 26, no. 10, pp. 2345-2350, 2006.

[75] M. M. Schoos, L. Munthe-Fog, M. O. Skjoedt et al., "Association between lectin pathway initiators, c-reactive protein and left ventricular remodeling in myocardial infarction-a magnetic resonance study," Molecular Immunology, vol. 54, no. 3-4, pp. 408-414, 2013.

[76] M. Trendelenburg, P. Theroux, A. Stebbins, C. Granger, P. Armstrong, and M. Pfisterer, "Influence of functional deficiency of complement mannose-binding lectin on outcome of patients with acute ST-elevation myocardial infarction undergoing primary percutaneous coronary intervention," European Heart Journal, vol. 31, no. 10, pp. 1181-1187, 2010.

[77] Y. M. Bilgin, A. Brand, S. P. Berger, M. R. Daha, and A. Roos, "Mannose-binding lectin is involved in multiple organ dysfunction syndrome after cardiac surgery: effects of blood transfusions," Transfusion, vol. 48, no. 4, pp. 601-608, 2008.

[78] L. T. Lai, D. C. Lee, W. Ko, K. Shevde, and M. Zhang, "Deficiency of complement factor MBL in a patient required cardiac surgery after an acute myocardial infarction with underlining chronic lymphocytic leukemia," International Journal of Cardiology, vol. 139, no. 2, pp. e24-e26, 2010.

[79] C. B. Holt, S. Thiel, K. Munk, H. Ostergaard, H. Botker, and T. Hansen, "Association between endogenous complement inhibitor and myocardial salvage in patients with myocardial infarction," European Heart Journal: Acute Cardiovascular Care, vol. 3, no. 1, pp. 3-9, 2014.

[80] S. Saevarsdottir, O. O. Oskarsson, T. Aspelund et al., "Mannan binding lectin as an adjunct to risk assessment for myocardial infarction in individuals with enhanced risk," Journal of Experimental Medicine, vol. 201, no. 1, pp. 117-125, 2005.

[81] I. T. Vengen, H. O. Madsen, P. Garred, C. Platou, L. Vatten, and V. Videm, "Mannose-binding lectin deficiency is associated with myocardial infarction: the HUNT2 study in Norway," Annals of Medicine, vol. 41, no. 8, pp. 591-598, 2009.

[82] L. G. Mellbin, A. Hamsten, K. Malmberg et al., "Mannosebinding lectin genotype and phenotype in patients with type 2 diabetes and myocardial infarction: a report from the DIGAMI 2 trial," Diabetes Care, vol. 33, no. 11, pp. 2451-2456, 2010.

[83] R. A. Matthijsen, M. P. de Winther, D. Kuipers et al., "Macrophage-specific expression of mannose-binding lectin controls atherosclerosis in low-density lipoprotein receptordeficient mice," Circulation, vol. 119, no. 16, pp. 2188-2195, 2009.

[84] A. Alipour, A. J. H. H. M. van Oostrom, J. P. H. van Wijk et al., "Mannose binding lectin deficiency and triglyceriderich lipoprotein metabolism in normolipidemic subjects," Atherosclerosis, vol. 206, no. 2, pp. 444-450, 2009.

[85] A. Shor and J. I. Phillips, "Histological and ultrastructural findings suggesting an initiating role for Chlamydia pneumoniae in the pathogenesis of atherosclerosis: a study of 50 cases," Cardiovascular Journal of South Africa, vol. 11, no. 1, pp. 16-23, 2000.

[86] R. Sessa, M. Di Pietro, G. Schiavoni et al., "Detection of Chlamydia pneumoniae in atherosclerotic coronary arteries," International Journal of Immunopathology and Pharmacology, vol. 17, no. 3, pp. 301-306, 2004.

[87] D. Virok, Z. Kis, L. Kari et al., "Chlamydophila pneumoniae and human cytomegalovirus in atherosclerotic carotid plaquescombined presence and possible interactions," Acta Microbiologica et Immunologica Hungarica, vol. 53, no. 1, pp. 35-50, 2006. 
[88] B. Atik, S. C. Johnston, and D. Dean, "Association of carotid plaque Lp-PLA(2) with macrophages and Chlamydia pneumoniae infection among patients at risk for stroke," PLOS ONE, vol. 5, no. 6, Article ID el1026, 2010.

[89] A. Luque, M. M. Turu, N. Rovira, J. O. Juan-Babot, M. Slevin, and J. Krupinski, "Early atherosclerotic plaques show evidence of infection by Chlamydia pneumoniae," Frontiers in Bioscience, vol. 4, pp. 2423-2432, 2012.

[90] A. F. Swanson, R. A. B. Ezekowitz, A. Lee, and C. Kuo, "Human mannose-binding protein inhibits infection of HeLa cells by Chlamydia trachomatis," Infection and Immunity, vol. 66, no. 4, pp. 1607-1612, 1998.

[91] S. Rugonfalvi-Kiss, V. Endrész, H. O. Madsen et al., "Association of Chlamydia pneumoniae with coronary artery disease and its progression is dependent on the modifying effect of mannosebinding lectin," Circulation, vol. 106, no. 9, pp. 1071-1076, 2002.

[92] L. N. Troelsen, P. Garred, and S. Jacobsen, "Mortality and predictors of mortality in rheumatoid arthritis-a role for mannose-binding lectin?" Journal of Rheumatology, vol. 37, no. 3, pp. 536-543, 2010.

[93] L. N. Troelsen, P. Garred, H. O. Madsen, and S. Jacobsen, "Genetically determined high serum levels of mannose-binding lectin and agalactosyl IgG are associated with ischemic heart disease in rheumatoid arthritis," Arthritis and Rheumatism, vol. 56, no. 1, pp. 21-29, 2007.

[94] M. H. Biezeveld, I. M. Kuipers, J. Geissler et al., "Association of mannose-binding lectin genotype with cardiovascular abnormalities in Kawasaki disease," The Lancet, vol. 361, no. 9365, pp. 1268-1270, 2003.

[95] M. H. Biezeveld, J. Geissler, G. J. Weverling et al., "Polymorphisms in the mannose-binding lectin gene as determinants of age-defined risk of coronary artery lesions in Kawasaki disease," Arthritis and Rheumatism, vol. 54, no. 1, pp. 369-376, 2006.

[96] D. Schmauss and M. Weis, "Cardiac allograft vasculopathy: recent developments," Circulation, vol. 117, no. 16, pp. 2131-2141, 2008.

[97] A. M. Segura and L. M. Buja, "Cardiac allograft vasculopathy," Texas Heart Institute Journal, vol. 40, no. 4, pp. 400-402, 2013.

[98] T. M. Millington and J. C. Madsen, "Innate immunity and cardiac allograft rejection," Kidney International. Supplement, vol. 78, no. 119, pp. S18-S21, 2010.

[99] W. M. Baldwin, M. Samaniego-Picota, E. K. Kasper et al., "Complement deposition in early cardiac transplant biopsies is associated with ischemic injury and subsequent rejection episodes," Transplantation, vol. 68, no. 6, pp. 894-900, 1999.

[100] A. E. Fiane, T. Ueland, S. Simonsen et al., "Low mannosebinding lectin and increased complement activation correlate to allograft vasculopathy, ischaemia, and rejection after human heart transplantation," European Heart Journal, vol. 26, no. 16, pp. 1660-1665, 2005.

[101] J. E. Fildes, S. M. Shaw, A. H. Walker et al., "Mannose binding lectin deficiency offers protection from acute graft rejection after heart transplantation," The Journal of Heart and Lung Transplantation, vol. 7, no. 11, pp. 2605-2614, 2007.

[102] P. Mejia and A. E. Davis III, "Cl inhibitor suppresses the endotoxic activity of a wide range of lipopolysaccharides and interacts with live gram-negative bacteria," Shock, vol. 38, no. 2, pp. 220-225, 2012.

[103] A. E. Davis III, P. Mejia, and F. Lu, "Biological activities of C1 inhibitor," Molecular Immunology, vol. 45, no. 16, pp. 4057-4063, 2008.
[104] E. W. Nielsen, C. Waage, H. Fure et al., "Effect of supraphysiologic levels of C1-inhibitor on the classical, lectin and alternative pathways of complement," Molecular Immunology, vol. 44, no. 8, pp. 1819-1826, 2007.

[105] A. E. Davis, F. Lu, and P. Mejia, "Cl inhibitor, a multi-functional serine protease inhibitor," Thrombosis and Haemostasis, vol. 104, no. 5, pp. 886-893, 2010.

[106] M. Buerke, T. Murohara, and A. M. Lefer, "Cardioprotective effects of a $\mathrm{Cl}$ esterase inhibitor in myocardial ischemia and reperfusion," Circulation, vol. 91, no. 2, pp. 393-402, 1995.

[107] M. Buerke, H. Schwertz, W. Seitz, J. Meyer, and H. Darius, "Novel small molecule inhibitor of C1s exerts cardioprotective effects in ischemia-reperfusion injury in rabbits," The Journal of Immunology, vol. 167, no. 9, pp. 5375-5380, 2001.

[108] G. Horstick, A. Heimann, O. Götze et al., "Intracoronary application of $\mathrm{Cl}$ esterase inhibitor improves cardiac function and reduces myocardial necrosis in an experimental model of ischemia and reperfusion," Circulation, vol. 95, no. 3, pp. 701708, 1997.

[109] G. Horstick, O. Berg, A. Heimann et al., "Application of C1esterase inhibitor during reperfusion of ischemic myocardium: dose-related beneficial versus detrimental effects," Circulation, vol. 104, no. 25, pp. 3125-3131, 2001.

[110] C. Schreiber, W. Heimisch, H. Schad et al., "C1-INH and its effect on infarct size and ventricular function in an acute pig model of infarction, cardiopulmonary bypass, and reperfusion," Thoracic and Cardiovascular Surgeon, vol. 54, no. 4, pp. 227-232, 2006.

[111] M. Buerke, D. Prüfer, M. Dahm, H. Oelert, J. Meyer, and H. Darius, "Blocking of classical complement pathway inhibits endothelial adhesion molecule expression and preserves ischemic myocardium from reperfusion injury," Journal of Pharmacology and Experimental Therapeutics, vol. 286, no. 1, pp. 429-438, 1998.

[112] F. Lu, S. M. Fernandes, and A. E. Davis III, "The effect of $\mathrm{C} 1$ inhibitor on myocardial ischemia and reperfusion injury," Cardiovascular Pathology, vol. 22, no. 1, pp. 75-80, 2013.

[113] J. Fu, G. Lin, Z. Wu et al., "Anti-apoptotic role for C1 inhibitor in ischemia/reperfusion-induced myocardial cell injury," Biochemical and Biophysical Research Communications, vol. 349, no. 2, pp. 504-512, 2006.

[114] R. Bauernschmitt, H. Böhrer, and S. Hagl, "Rescue therapy with C1-esterase inhibitor concentrate after emergency coronary surgery for failed PTCA," Intensive Care Medicine, vol. 24, no. 6, pp. 636-638, 1998.

[115] C. de Zwaan, A. H. Kleine, J. H. C. Diris et al., "Continuous 48-h C1-inhibitor treatment, following reperfusion therapy, in patients with acute myocardial infarction," European Heart Journal, vol. 23, no. 21, pp. 1670-1677, 2002.

[116] M. Thielmann, G. Marggraf, M. Neuhäuser et al., "Administration of C1-esterase inhibitor during emergency coronary artery bypass surgery in acute ST-elevation myocardial infarction," European Journal of Cardio-Thoracic Surgery, vol. 30, no. 2, pp. 285-293, 2006.

[117] K. Fattouch, G. Bianco, G. Speziale et al., "Beneficial effects of $\mathrm{Cl}$ esterase inhibitor in ST-elevation myocardial infarction in patients who underwent surgical reperfusion: a randomised double-blind study," European Journal of CardioThoracic Surgery, vol. 32, no. 2, pp. 326-332, 2007.

[118] Y. Banz and R. Rieben, "Role of complement and perspectives for intervention in ischemia-reperfusion damage," Annals of Medicine, vol. 44, no. 3, pp. 205-217, 2012. 
[119] J. C. K. Fitch, S. Rollins, L. Matis et al., "Pharmacology and biological efficacy of a recombinant, humanized, single-chain antibody C5 complement inhibitor in patients undergoing coronary artery bypass graft surgery with cardiopulmonary bypass," Circulation, vol. 100, no. 25, pp. 2499-2506, 1999.

[120] C. B. Granger, K. W. Mahaffey, W. D. Weaver et al., "Pexelizumab, an anti-C5 complement antibody, as adjunctive therapy to primary percutaneous coronary intervention in acute myocardial infarction: the COMplement inhibition in Myocardial infarction treated with Angioplasty (COMMA) trial," Circulation, vol. 108, no. 10, pp. 1184-1190, 2003.

[121] K. W. Mahaffey, C. B. Granger, J. C. Nicolau et al., "Effect of pexelizumab, an anti-C5 complement antibody, as adjunctive therapy to fibrinolysis in acute myocardial infarction: the COMPlement inhibition in myocardial infarction treated with thromboLYtics (COMPLY) trial," Circulation, vol. 108, no. 10, pp. 1176-1183, 2003.

[122] S. K. Shernan, J. C. K. Fitch, N. A. Nussmeier et al., "Impact of pexelizumab, an anti-C5 complement antibody, on total mortality and adverse cardiovascular outcomes in cardiac surgical patients undergoing cardiopulmonary bypass," Annals of Thoracic Surgery, vol. 77, no. 3, pp. 942-949, 2004.

[123] E. D. Verrier, S. K. Shernan, K. M. Taylor et al., "Terminal complement blockade with pexelizumab during coronary artery bypass graft surgery requiring cardiopulmonary bypass: a randomized trial," Journal of the American Medical Association, vol. 291, no. 19, pp. 2319-2327, 2004.

[124] P. W. Armstrong, C. B. Granger, P. X. Adams et al., "Pexelizumab for acute ST-elevation myocardial infarction in patients undergoing primary percutaneous coronary intervention: a randomized controlled trial," Journal of the American Medical Association, vol. 297, pp. 43-51, 2007.

[125] L. Testa, W. J. van Gaal, R. Bhindi et al., "Pexelizumab in ischemic heart disease: a systematic review and meta-analysis on 15,196 patients," Journal of Thoracic and Cardiovascular Surgery, vol. 136, no. 4, pp. 884-893, 2008. 


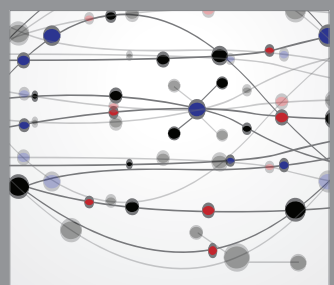

The Scientific World Journal
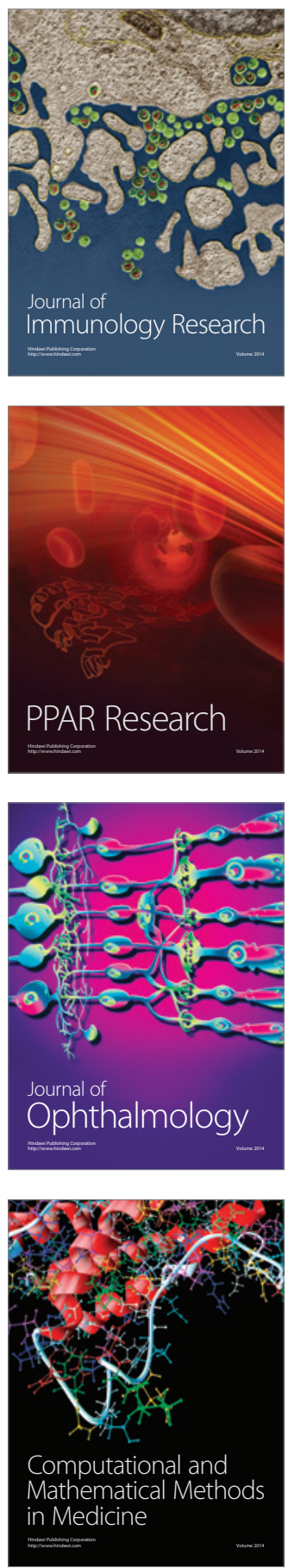

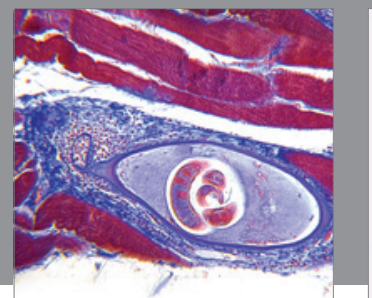

Gastroenterology

Research and Practice
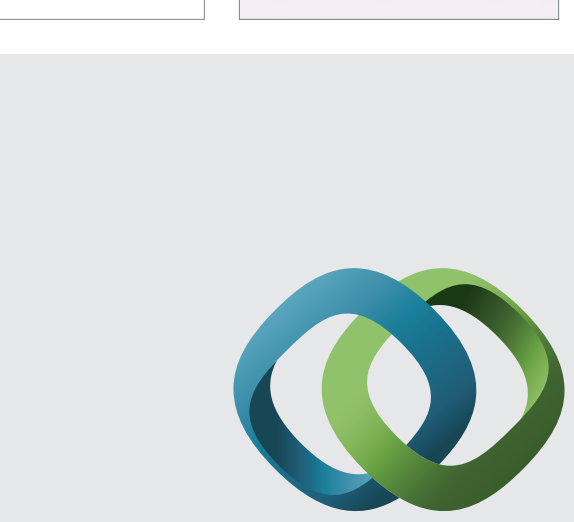

\section{Hindawi}

Submit your manuscripts at

http://www.hindawi.com
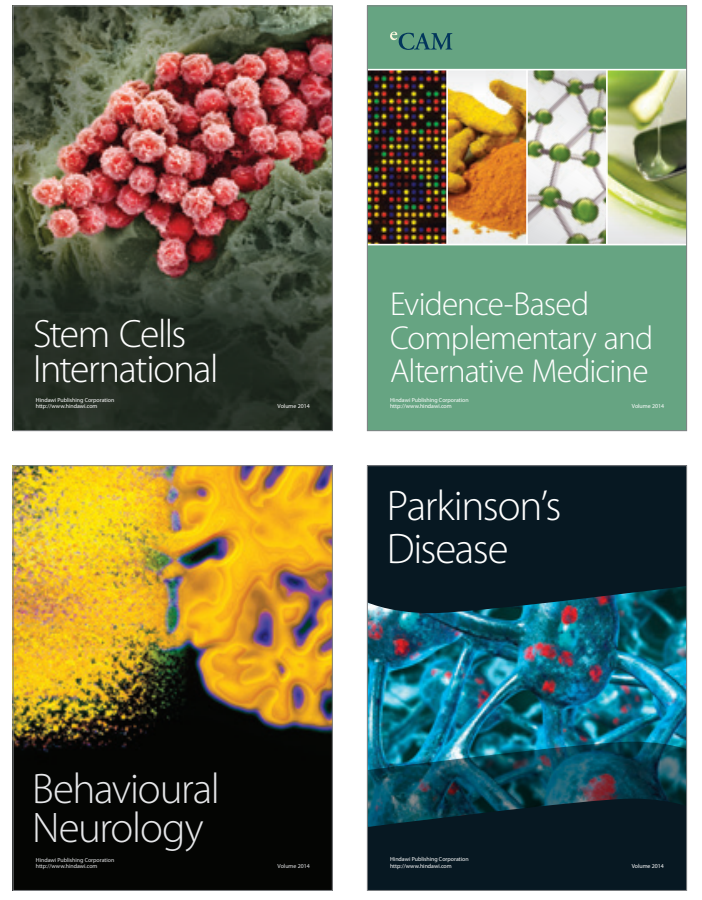
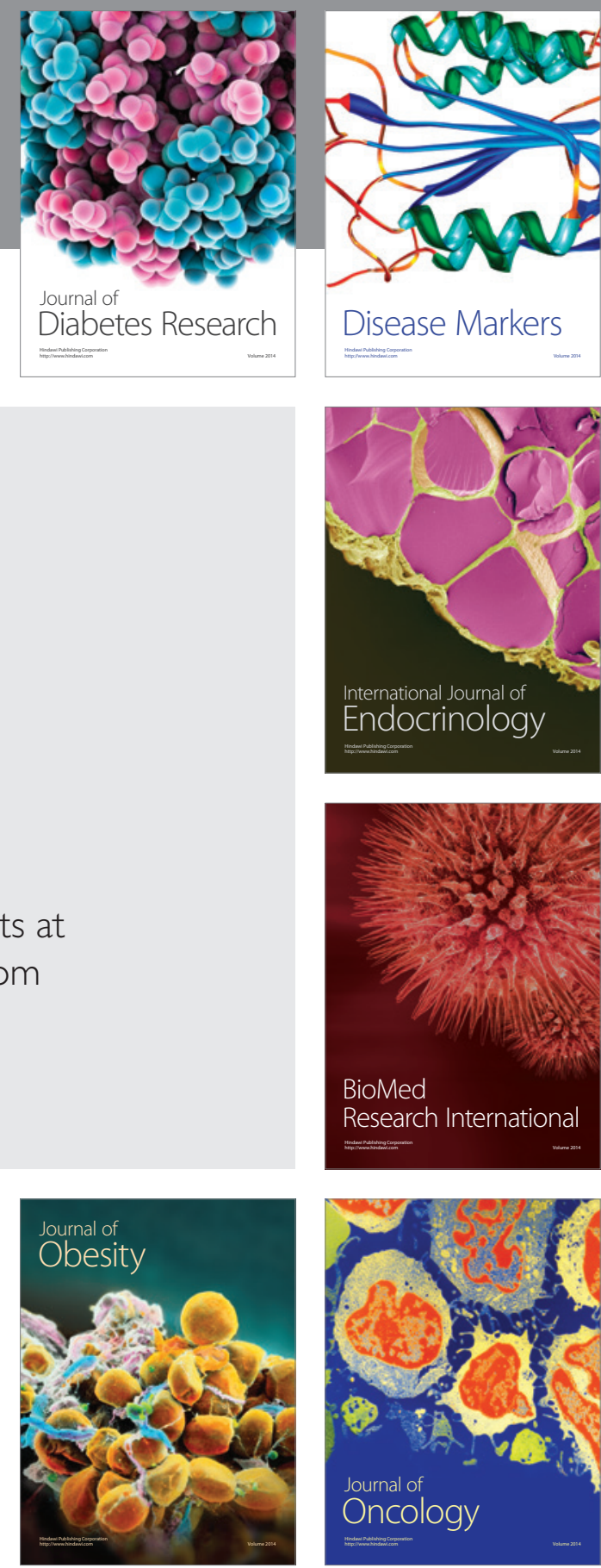

Disease Markers
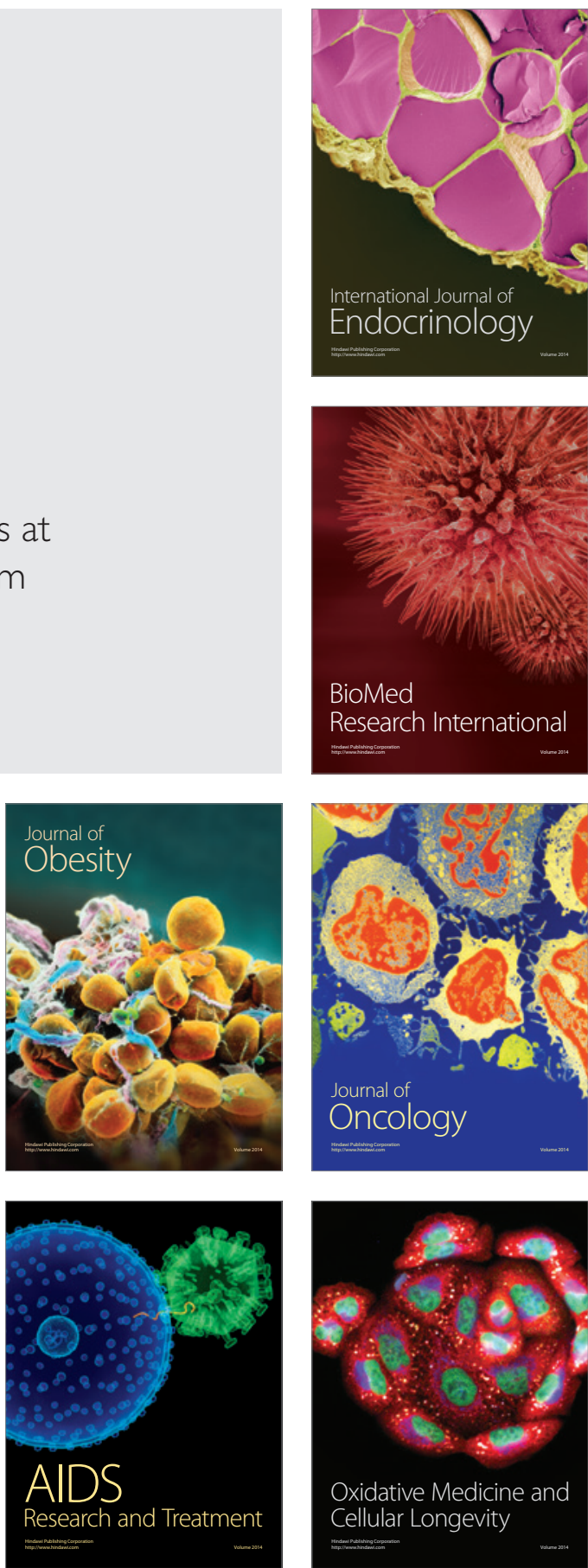